\title{
Neurocognitive functioning and health-related quality of life in adult medulloblastoma patients: long-term outcomes of the NOA-07 study
}

\author{
Linda Dirven ${ }^{1,2} \cdot$ Ralf Luerding $^{3} \cdot$ Dagmar Beier $^{4} \cdot$ Elisabeth Bumes $^{3} \cdot$ Christiane Reinert $^{3,5} \cdot$ Clemens Seidel $^{6}$. \\ Matteo Mario Bonsanto ${ }^{7}$. Michael Bremer ${ }^{8}$. Stefan Rieken ${ }^{9}$. Stephanie E. Combs ${ }^{10,11,12}$. Ulrich Herrlinger ${ }^{13}$. \\ Corinna Seliger ${ }^{3,14,15} \cdot$ Holger Kuntze $^{16} \cdot$ Regine Mayer-Steinacker $^{17} \cdot$ Annette Dieing $^{18} \cdot$ Claudius Bartels $^{19}$. \\ Oliver Schnell ${ }^{20}$. Astrid Weyerbrock ${ }^{20}$. Sabine Seidel ${ }^{21}$. Oliver Grauer ${ }^{22} \cdot$ Minou Nadji-Ohl $^{23} \cdot$ Frank Paulsen $^{24}$. \\ Michael Weller ${ }^{25}$. Wolfgang Wick ${ }^{14,15} \cdot$ Peter $\mathrm{Hau}^{3}$
}

Received: 11 January 2020 / Accepted: 9 April 2020 / Published online: 4 May 2020

(c) The Author(s) 2020

\begin{abstract}
Background Combined radiochemotherapy followed by maintenance chemotherapy with cisplatin, lomustine and vincristine within the NOA-07 study resulted in considerable short-term toxicity in adult medulloblastoma patients. Here we investigated the long-term impact of this treatment, focusing on neurocognitive functioning and health-related quality of life (HRQoL). Methods Neurocognitive functioning and HRQoL scores over time were determined, and differences between the posttreatment and follow-up assessments were calculated up to 18 months for neurocognition and 60 months for HRQoL.

Results 28/30 patients were analyzed. The three preselected HRQoL scales (role, social and cognitive functioning) showed improved scores, to a clinically relevant extent ( $\geq 10$ points), compared to post-treatment levels up to 30 months, but decreased afterwards. Z-scores for verbal working memory were worse during follow-up compared to post-treatment scores and remained impaired during 18 months follow-up (i.e. z-score below - 1 standard deviation). Attention was impaired post-treatment, and remained impaired to a clinically relevant extent during follow-up. Coordination/processing speed and lexical verbal fluency improved compared to post-treatment scores, and remained within the normal range thereafter. Other tests of verbal fluency were stable over time, with z-scores within the normal range.

Conclusions This long-term follow-up study showed that the NOA-07 treatment regimen was not associated with a deterioration in HRQoL in the post-treatment period. Verbal working memory deteriorated, while other neurocognitive domains did not seem to be impacted negatively by the treatment.
\end{abstract}

Keywords Brain tumor $\cdot$ Medulloblastoma $\cdot$ Cognition $\cdot$ Quality of life $\cdot$ Patient-reported outcome $\cdot$ Toxicity

\section{Introduction}

Medulloblastoma is a rare entity in adults, with an incidence of 0.6 cases per million persons per year [1]. Within the adult population, the disease typically affects young adults, at a median age between 20 and 40 years [2-4]. Current

Linda Dirven and Ralf Luerding have contributed equally.

Electronic supplementary material The online version of this article (https://doi.org/10.1007/s11060-020-03502-y) contains supplementary material, which is available to authorized users.

Peter Hau

peter.hau@ukr.de

Extended author information available on the last page of the article standard of care consists of surgery, radiotherapy and/or chemotherapy, but newer therapies including immunotherapy and targeted therapy are being explored, particularly in the pediatric population [5]. Despite multimodal antitumor treatment, tumor recurrence is inevitable in part of the patients. Recently reported 5- and 10-year overall survival rates ranged between 74 and $82 \%[1,4,6]$ and between 65 and $67 \%$, respectively $[1,6]$, and depend on clinical characteristics of patients and the histological and genetic profile of the tumor. [3, 4, 6-8].

Medulloblastoma patients may suffer from a variety of symptoms, depending on the tumor location $[9,10]$ and its subsequent treatment. Anti-tumor treatment may alleviate the symptoms caused by the tumor, but may also result in early and late toxicity $[2,3,11]$. In the short-term, patients 
with medulloblastoma may experience problems with coordination and gait. Increased intracranial pressure may cause symptoms such as headache, nausea and vomiting. When metastasized to the cerebrospinal fluid, back pain, muscle weakness, and loss of bladder and bowel function are frequent problems. Common acute toxicities in adult patients with medulloblastoma treated with radiochemotherapy are bone marrow suppression, polyneuropathy and ototoxicity [2].

As medulloblastoma patients have a relatively long survival, the impact of treatment on the patients' longterm functioning and well-being should also be considered during treatment decision-making. Most of the long-term adverse effects are not self-limiting. One of the most relevant long-term complications of radiotherapy in brain tumor patients is neurocognitive dysfunction [12], which may subsequently interfere with a patients' functioning in daily life, particularly role and social functioning. Although it has been shown that a large proportion of adult medulloblastoma patients have impaired neurocognitive functioning shortly after diagnosis, particularly in the domains learning, memory, and executive function [13], data on the short- and long-term impact of treatment on outcomes such as neurocognition and HRQoL are limited. One study reported impaired executive function, weakness, ataxia, depression and anxiety about nine years after radiotherapy [14]. A review on core deficits and quality of survival in childhood medulloblastoma survivors showed long-term neurological and sensory (e.g. hearing loss) problems, endocrine dysfunction, neurocognitive impairments (particularly in the domains information processing speed, attention and working memory) and psychosocial problems, particularly with role and social functioning [15]. In knowledge of these possible short- and long-term side effects, information on both the quantity and quality of survival should be available when informing patients on the benefits and risks of a treatment strategy. The NOA-07 study investigated a combined radiochemotherapy of the neuroaxis with a boost to the posterior fossa in combination with vincristine, followed by maintenance chemotherapy with cisplatin, lomustine and vincristine with the main endpoint of toxicity-related treatment terminations after four cycles of adjuvant chemotherapy, and the acute toxicity profile in adult patients. Previously, the short-term impact of treatment in this study was investigated, showing considerable toxicity during active treatment, but improvements in HRQoL and neurocognitive functioning [2]. Here we describe the long-term disease burden, up to five years after diagnosis, of adult medulloblastoma patients treated in the NOA-07 study in terms of neurocognitive functioning and health-related quality of life (HRQoL), which were secondary endpoints.

\section{Methods}

\section{Study population}

Adult (age $\geq 21$ years) medulloblastoma patients with a Chang stage T1-4 and M0 or M1 were included. Further details on the study population are available elsewhere [2]. The study was approved by the ethical review boards of all participating centers, and patients provided written informed consent before participation.

\section{Study design and treatment}

NOA-07 was a prospective study in which all patients received photon craniospinal irradiation $(35.2 \mathrm{~Gy}$ in 22 fractions of $1.6 \mathrm{~Gy}$, with a posterior fossa boost of $55 \mathrm{~Gy}$ in fractions of $1.8 \mathrm{~Gy})$ in combination with vincristine $(1.5 \mathrm{mg} /$ $\mathrm{m}^{2}$ per week), followed by a maximum of eight six-week cycles of cisplatin $\left(70 \mathrm{mg} / \mathrm{m}^{2}\right.$; day 1$)$, lomustine $\left(75 \mathrm{mg} / \mathrm{m}^{2}\right.$; day 1$)$ and vincristine $\left(1.5 \mathrm{mg} / \mathrm{m}^{2}\right.$; days 1,8 and 15$)$. Further details on the treatment schedule have been published previously [2].

\section{Outcomes}

Primary endpoints of NOA-07 study were toxicity-related treatment terminations after four cycles of adjuvant chemotherapy, and acute toxicity profile. Event-free, progressionfree and overall survival were secondary endpoints, as were neurocognitive functioning and HRQoL.

\section{Neurocognitive functioning}

A neurocognitive test battery was used to assess several relevant domains. Since the representations of working memory, word fluency and attention involve cerebellar functions to a substantial level [16-19], these domains were chosen. The digit span forward and backward test from the German version of the Wechsler Adult Intelligence Scale-Revised [20] was used to assess attention span and verbal working memory. Trail Making Test Parts A and B [21] were used to measure coordination/processing speed and divided attention. Lexical verbal fluency was assessed with the Controlled Oral Word Association (COWA) test [22], while semantic verbal fluency was measured with the Regensburger Wortfluessigkeitstest [23]. To reduce practice effects, tests were chosen with minimal effects by repeated measurements [24]. Raw test scores were converted into z-scores, adjusting for age, sex and education, using population-based, normative data (means and standard deviations), provided by the respective test author in the test manual. A difference in $\mathrm{z}$-score of -1 standard deviation (SD) 
was chosen as cut-off to indicate impaired performance of patients as compared to the norm population, as well as to indicate a clinically relevant change over time [2, 19, 25]. Neurocognitive functioning was evaluated between resection and the start of combined radiochemotherapy and after adjuvant chemotherapy, and subsequently every three months for up to 24 months, after which neurocognition was assessed every six months up to 60 months.

\section{HRQoL}

The EORTC core Quality of Life Questionnaire (QLQ-C30, version 3.0) was used in combination with the brain cancer module (QLQ-BN20). Both instruments have shown robust psychometric properties [26-28]. Following the EORTC scoring manual, raw item scores were aggregated and transformed into linear scales ranging from 0 to 100 [29]. For functional scales, a higher score represents better functioning, while for the symptom scales/items a higher score represents a higher level of symptoms. A difference $\geq 10$ points on any scale/item was deemed clinically relevant [30]. HRQoL was evaluated between resection and the start of combined radiochemotherapy, after the conclusion of adjuvant chemotherapy, and subsequently every 3 months thereafter for up to 24 months, after which HRQoL was assessed every six months up to 60 months. Based on clinical experience, longterm social outcome was considered most relevant to adult medulloblastoma patients, who are typically younger adults with an active family and social life. Therefore, three scales were selected for primary analysis: role functioning (RF), cognitive functioning (CF) and social functioning (SF). All other scales/items were analyzed on an exploratory basis.

\section{Statistical analysis}

\section{Descriptive statistics}

Sociodemographic and clinical characteristics of the patients included in this study were reported by means of descriptive statistics, as were (changes in) neurocognitive functioning and HRQoL scores. Patients with data available at the moment of disease progression were included in the analyses. Compliance with neurocognitive and HRQoL assessments as determined for each included follow-up moment was calculated by dividing the number of completed tests or HRQoL forms at a specific time point by the number of expected test scores or forms at that moment.

\section{Longitudinal course of neurocognitive functioning and HRQoL}

Graphs were constructed to assess neurocognitive functioning and HRQoL scores over time, and a visual description provided accordingly. Wilcoxon signed rank test was used to calculate whether the differences between the post-treatment and follow-up neurocognitive and HRQoL scores were statistically significant, but these analyses should be considered exploratory due to the limited number of patients. In addition, the percentage of patients with impaired neurocognitive functioning was calculated at each time point, separately for each domain.

A sub-analysis was performed in those patients with follow-up HRQoL data beyond 36 months, to gain more insight into their HRQoL trajectory. To do so, an average score during treatment was compared with the average score during long-term follow-up, which was defined as the average in a specific HRQoL scale score between 36 and 60 months follow-up.

All statistical analyses were done with SPSS version 25.0 (Armonk, NY: IBM Corp), and a p-value $<0.05$ was considered statistically significant.

\section{Results}

A total of 28 out of 30 eligible patients completed at least one valid HRQoL questionnaire or underwent neurocognitive testing and were included in this analysis. Included patients were on average 37 (SD 10) years of age, the majority $(61 \%)$ was male, and the median KPS at inclusion was 90. Most tumors were in the classic and desmoplastic/ nodular entities. All patients had undergone resection and received combined radiochemotherapy. Eighty-nine percent of patients received at least one cycle of chemotherapy (median 6; range 0-8). During follow-up, five patients had disease progression after a median of 1.8 years (range 1.1-4.5), and the 3- and 5-year event-free survival rate was $66.6 \%$ each. The progression-free and overall survival rates were $66.6 \%$ for PFS after 3- and 5-years, and $70 \%$ for OS after 3 - and 5-years, respectively (Table 1).

\section{Compliance with HRQoL and neurocognitive assessments}

At the pre-treatment assessment, compliance with HRQoL assessments was $86 \%$, which decreased over time to $33 \%$ after 5 years of follow-up (Fig. 1). The average compliance rate for HRQoL over time was $65 \%$. For neurocognitive testing these percentages were slightly lower: $50 \%$ compliance at the pre-treatment assessment, which dropped to $11 \%$ after 5 years of follow-up. Because compliance was $<30 \%$ from 18 months onwards for neurocognitive testing, these analyses were conducted up to 18 months only. Reasons for drop-out were the decision of the investigator to terminate treatment ( $8 \%)$, toxicity $(29 \%)$, withdrawal of consent $(29 \%)$, non-compliance $(8 \%)$ and progressive disease 
Table 1 Baseline sociodemographic and clinical characteristics of medulloblastoma patients in the NOA-07 study who completed at least one valid health-related quality of life form or underwent neurocognitive testing at least once

Baseline characteristics $(n=28)$

\begin{tabular}{ll}
\hline Age in years at diagnosis & \\
Mean (SD; range) & $37(10 ; 22-54)$ \\
Gender, no. (\%) & $17(61 \%)$ \\
Male & $11(39 \%)$ \\
Female & $90(50-100)$ \\
KPS, median (range) & \\
Histopathological entity, no. (\%) & $12(43 \%)$ \\
Classic & $14(50 \%)$ \\
Desmoplastic/nodular & $2(7 \%)$ \\
Other & \\
Molecular entity, no. (\%) & $18(64.3 \%)$ \\
SHH-driven, p53wt & - \\
SHH-driven, p53mut & $4(14.3 \%)$ \\
WNT-driven & - \\
Group 3 & $5(17.9 \%)$ \\
Group 4 & $1(3.5 \%)$ \\
Not available & $28(100 \%)$ \\
Radiochemotherapy completed & $25(89 \%)$ \\
Adjuvant chemotherapy received & $6(0-8)$ \\
Chemotherapy cycles, median (range) & $5(18 \%)$ \\
Disease progression, no. (\%) & $1.8(1.1-4.5)$ \\
Progression-free survival in years, median & \\
(range); (n=5) & $70 \%$ \\
5-year overall survival rate (\%) & \\
\hline
\end{tabular}

(25\%). See Supplemental Table 1 for the clinical characteristics of patients included in the 18-month neurocognitive assessments.

\section{Health-related quality of life}

As previously reported [2], treatment resulted in an improvement of role, cognitive and social functioning on the group level [2]. Compared to post-treatment scores, none of the follow-up scores was significantly different for any of the preselected scales. Although the numbers of patients decreased over time, resulting in a limited number of patients available for analysis ( $<10$ patients beyond 36 months followup), the results show that role functioning did improve to a clinically relevant extent compared to post-treatment levels up to 30 months, but decreased afterwards. Similar trends were observed for cognitive and social functioning (Fig. 2), and also for the exploratory HRQoL scales/items (data not shown).

To gain more insight into the HRQoL trajectory of those patients with available long-term follow-up data (i.e. $\geq 36$ months), we compared scores during treatment with those during long-term follow-up. For the 12 eligible patients, we found that the average score for social functioning was higher at long-term follow-up than during treatment (77 vs. 50, $\mathrm{p}=0.006$ ). For role and cognitive functioning, treatment and long-term follow-up scores were not different; respectively 69 vs. $81(\mathrm{p}=0.126)$ for role functioning, and 73 vs. $69(\mathrm{p}=0.397)$ for cognitive functioning.

$S D$ standard deviation, KPS Karnofsky Performance Status

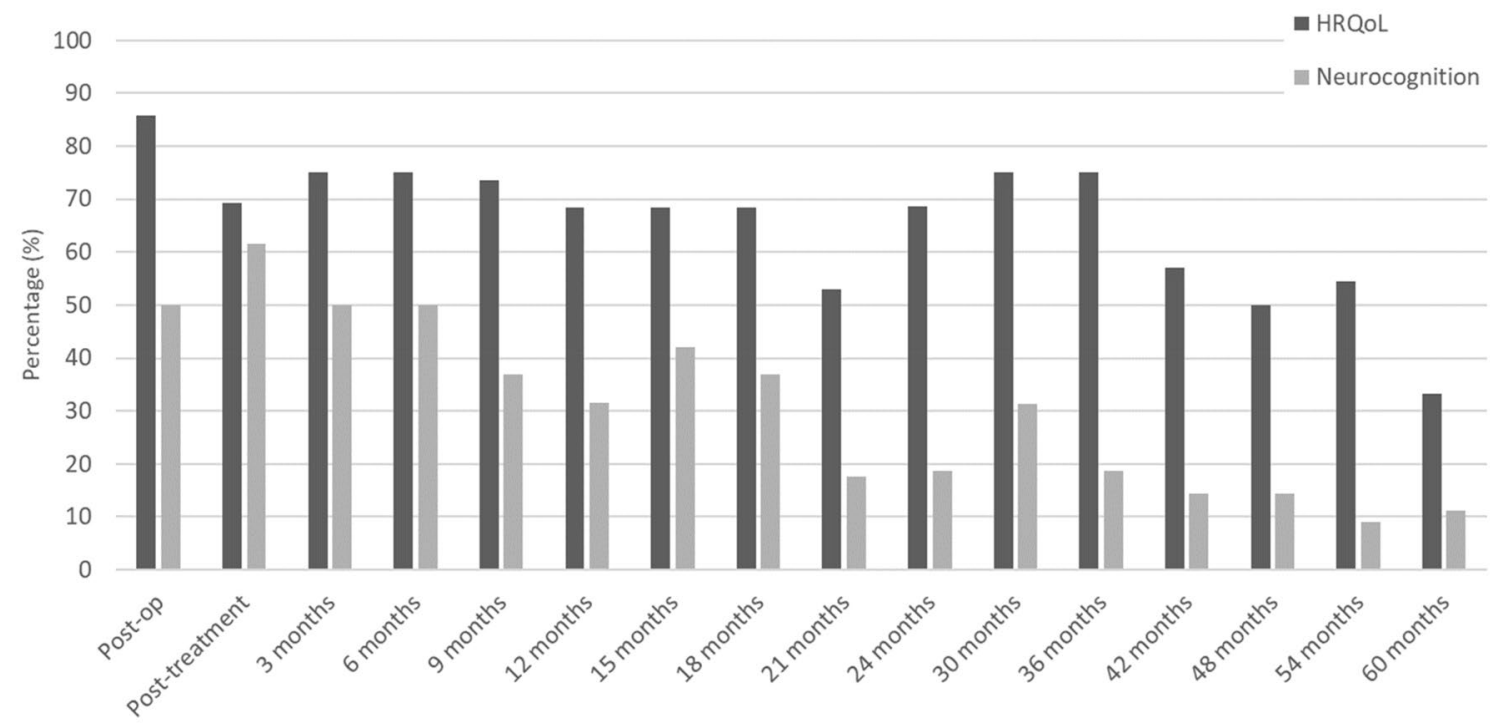

Fig. 1 Compliance with health-related quality of life assessments and neurocognitive testing 


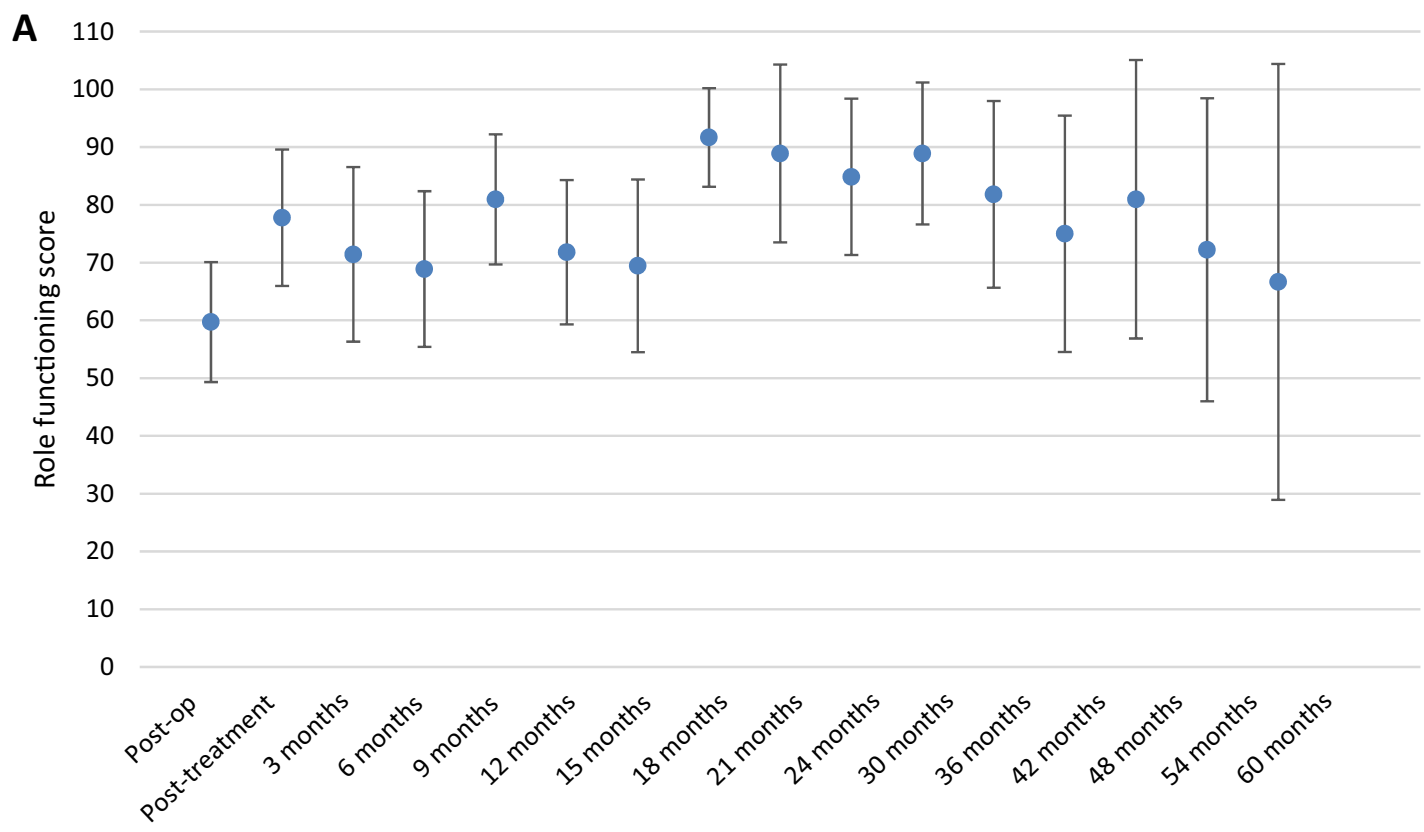

Number of patients with HRQoL data

$$
\begin{array}{llllllllllllllll}
24 & 18 & 14 & 15 & 14 & 13 & 12 & 12 & 9 & 11 & 12 & 11 & 8 & 7 & 6 & 3
\end{array}
$$

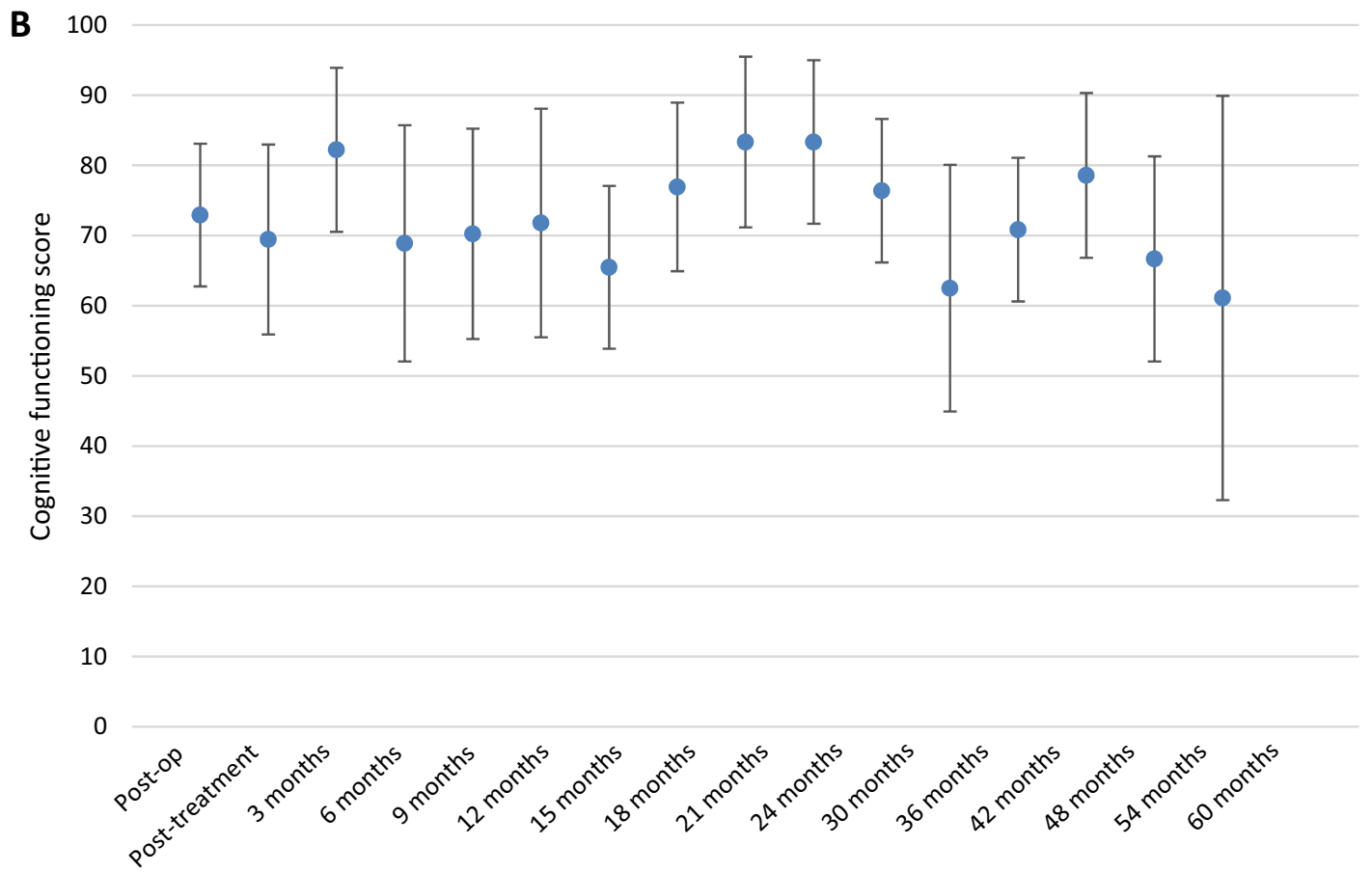

Number of patients with HRQoL data

$$
\begin{array}{llllllllllllllll}
24 & 18 & 15 & 15 & 14 & 13 & 14 & 13 & 9 & 11 & 12 & 12 & 8 & 7 & 6 & 3
\end{array}
$$

Fig. 2 Mean health-related quality of life scores and its 95\% confidence interval over time, from the postoperative assessment (before radiochemotherapy) up to five years of follow-up for the preselected scales a role functioning, $\mathbf{b}$ cognitive functioning and $\mathbf{c}$ social functioning 


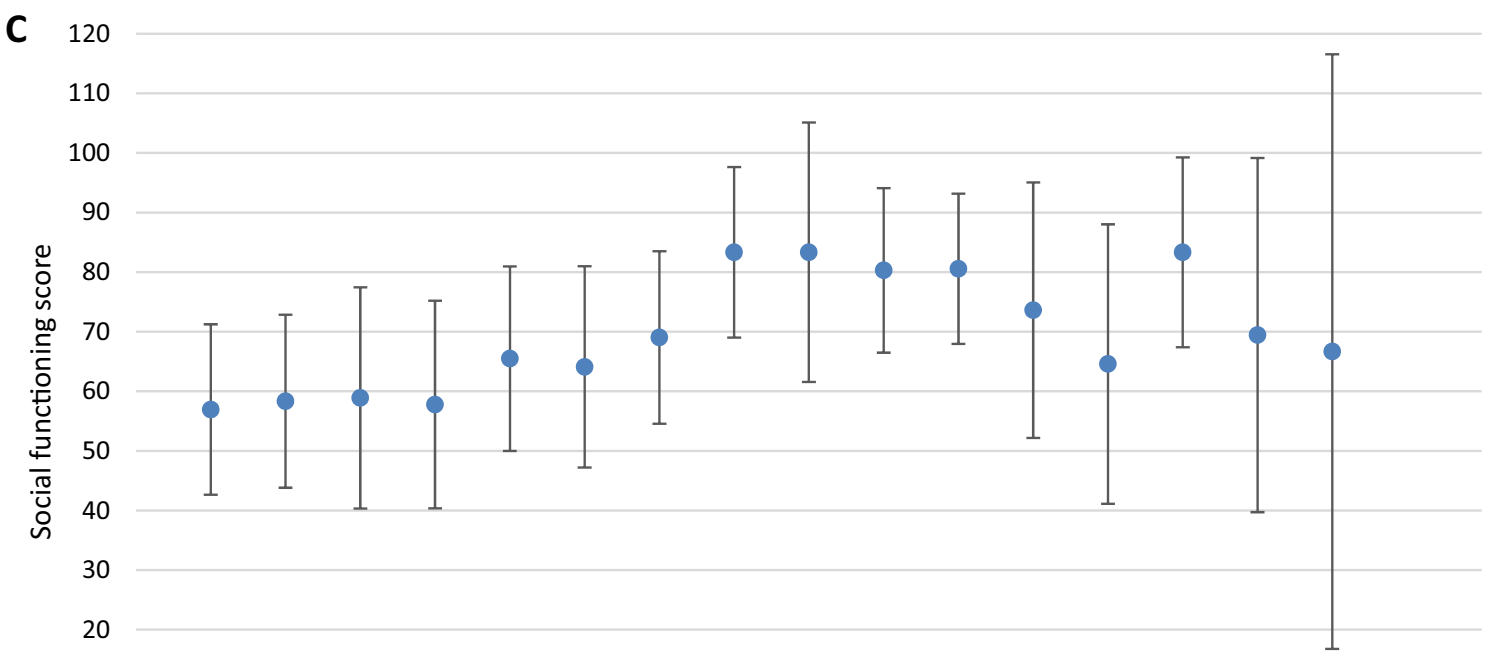

10

0

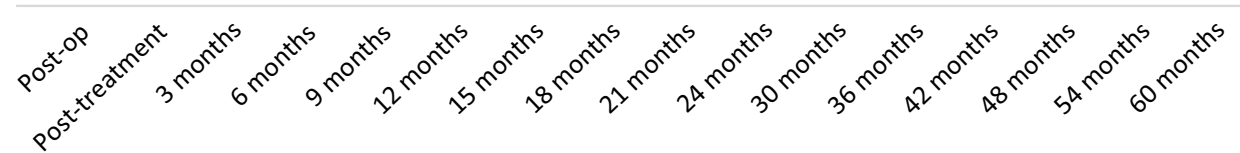

Number of patients with HRQoL data

$$
\begin{array}{llllllllllllllll}
24 & 18 & 15 & 15 & 14 & 13 & 14 & 13 & 9 & 11 & 12 & 12 & 8 & 7 & 6 & 3
\end{array}
$$

Fig. 2 (continued)

\section{Neurocognitive functioning}

The median number of tests on which patients had impaired neurocognitive functioning was 3 before treatment, 3.5 after treatment and ranged between 1.5 and 3.5 during follow-up (Table 2).

\section{Attention span and verbal working memory}

The digit span forward test showed that the mean z-scores during follow-up were lower than the post-treatment $\mathrm{z}$-scores: 0.4 during the post-treatment assessment versus -1.79 at 3 months follow-up $(p=0.012)$ and -1 at the 18-month assessment $(\mathrm{p}=0.027)$, indicating the bottom of normal performance. The amelioration between the 3- and 18 -month assessment was significant $(\mathrm{p}=0.043)$, but not clinically relevant (Fig. 3a). The findings on group level are supported by the findings on individual patient levels, showing that the percentage of impaired patients increased from $19 \%$ post-treatment to between 50 and $90 \%$ during follow-up (Table 2).

Whereas the digit span backward test was in the normal range before and directly after the treatment, working memory was impaired (z-score $>-1)$ at all time points except after 9 months follow-up (z-score $=-0.8$ ) (Fig. 3b). Differences were statistically significant and clinically

Table 2 Percentage of patients with impaired neurocognitive functioning (z-score $<-1 \mathrm{SD}$ ) over time, separately for each domain

\begin{tabular}{|c|c|c|c|c|c|c|c|c|}
\hline & Pre-treatment & Post-treatment & $3 \mathrm{~m} \mathrm{FU}$ & $6 \mathrm{~m} \mathrm{FU}$ & $9 \mathrm{~m} \mathrm{FU}$ & $12 \mathrm{~m} \mathrm{FU}$ & $15 \mathrm{~m} \mathrm{FU}$ & $18 \mathrm{~m} \mathrm{FU}$ \\
\hline Trail I & 4 & 10 & 5 & $4 / 10$ & $1 / 7$ & $3 / 6$ & $2 / 7$ & $1 / 6(17 \%)$ \\
\hline Test-B & $9 / 14(6$ & $11 / 16(6$ & $7 / 10(7$ & $8 / 10(80 \%)$ & $4 / 7(57 \%)$ & $2 / 6$ & $4 / 7(5$ & $0 \%)$ \\
\hline Digit span forward & $1 / 14(7 \%)$ & $3 / 16(19 \%)$ & $9 / 10(90 \%)$ & $6 / 10(60 \%)$ & $6 / 7(86 \%)$ & $3 / 6(50 \%)$ & $6 / 8(75 \%)$ & $5 / 7(71 \%)$ \\
\hline Digit span backward & $2 / 14(14 \%)$ & $5 / 16(31 \%)$ & $8 / 10(80 \%)$ & $6 / 10(60 \%)$ & $3 / 7(43 \%)$ & $4 / 6(67 \%)$ & $4 / 8(50 \%)$ & $5 / 7(71 \%)$ \\
\hline Lexical fluency & $10 / 13(77 \%)$ & $10 / 14(71 \%)$ & $2 / 10(20 \%)$ & $3 / 10(30 \%)$ & $2 / 7(29 \%)$ & $1 / 6(17 \%)$ & $3 / 8(38 \%)$ & $3 / 7(43 \%)$ \\
\hline Animal naming & $5 / 14(36 \%)$ & $8 / 16(50 \%)$ & $1 / 10(10 \%)$ & $4 / 10(40 \%)$ & $1 / 7(14 \%)$ & $1 / 6(17 \%)$ & $4 / 8(50 \%)$ & $3 / 7(43 \%)$ \\
\hline Food naming & $6 / 13(46 \%)$ & $7 / 14(50 \%)$ & $2 / 10(20 \%)$ & $4 / 10(40 \%)$ & $2 / 7(29 \%)$ & $1 / 6(17 \%)$ & $3 / 8(38 \%)$ & $2 / 7(29 \%)$ \\
\hline Median (range) tests impaired & $3(1-6)$ & $3.5(0-7)$ & $3.5(1-5)$ & $3.5(1-6)$ & $3(0-5)$ & $1.5(0-5)$ & $3.5(0-6)$ & $3(0-6)$ \\
\hline
\end{tabular}


Fig. 3 Mean Z-scores and 95\% confidence interval for the different neurocognitive tests over time; a Attention span (digit span forward), $\mathbf{b}$ working memory (digit span backward), c divided attention (Trail Making Test B), $\mathbf{d}$ coordination/ processing speed (Trail Making Test A), e lexical word fluency, $\mathbf{f}$ animal naming, and $\mathbf{g}$ food naming

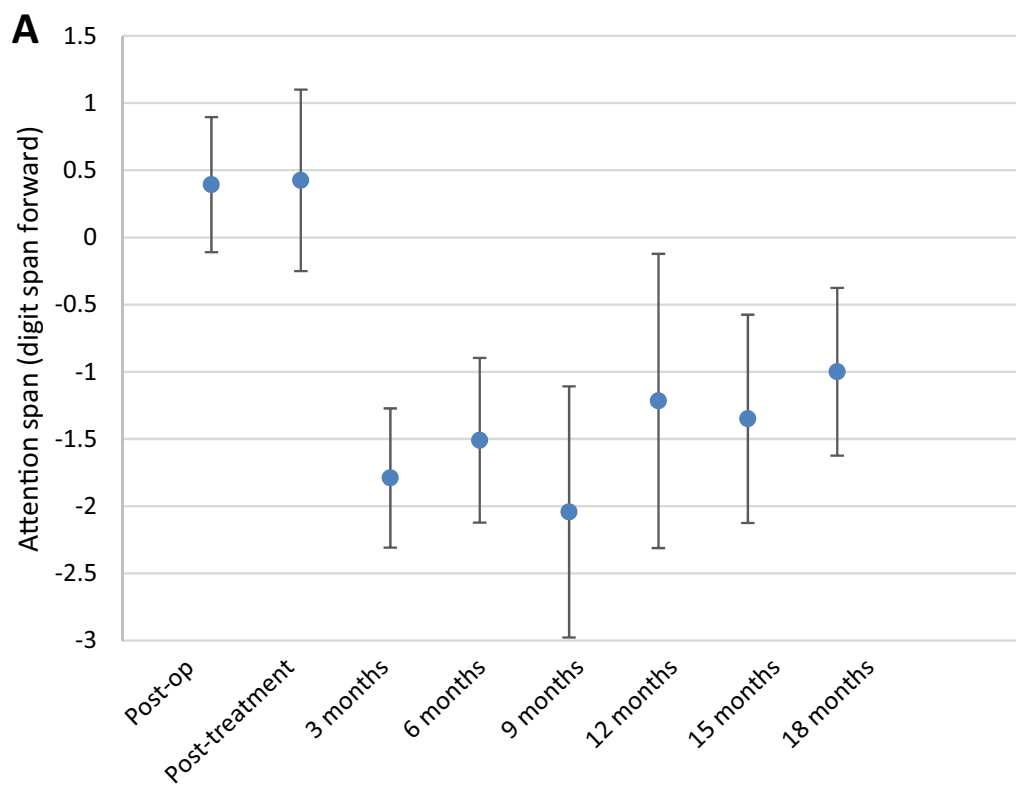

Number of patients with neurocognitive data
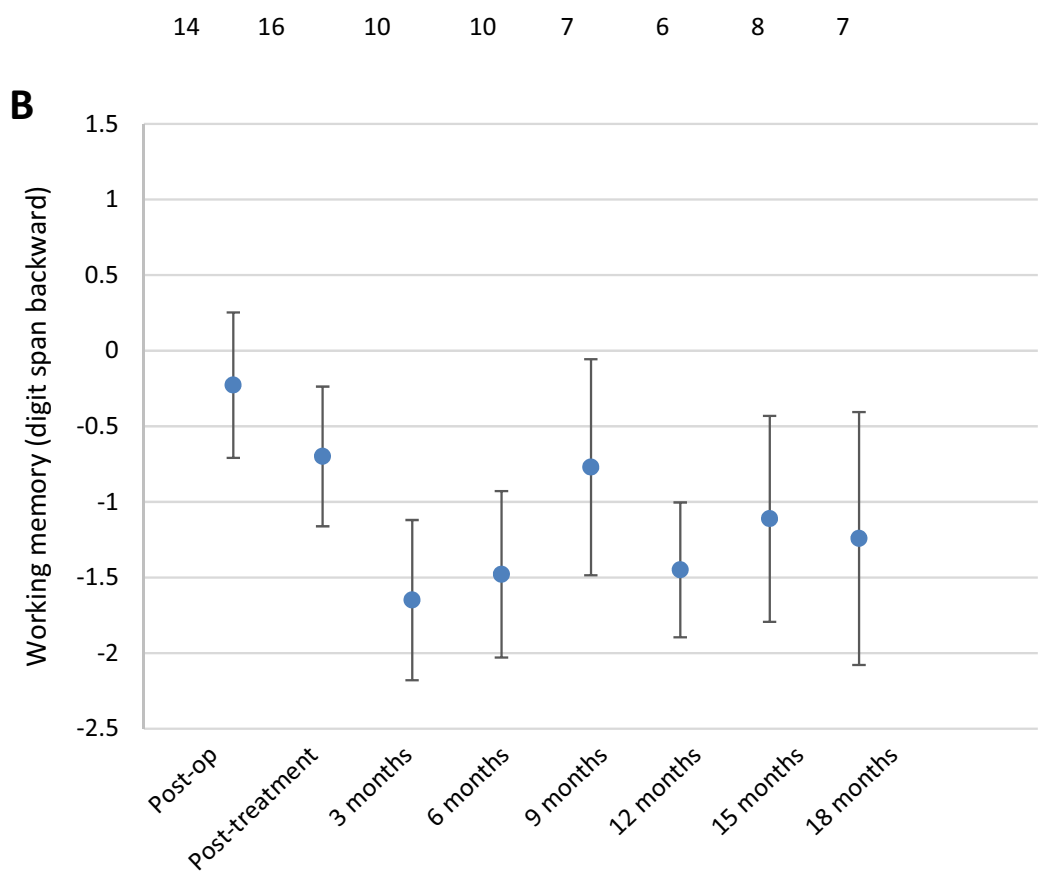

Number of patients with neurocognitive data relevant between the post-treatment z-score and the 3and 6-month follow-up assessment $\mathrm{z}$-scores $(\mathrm{p}=0.027$ and $p=0.028$, respectively). On the individual patient level, the results also indicated that the majority of patients had impaired working memory over time, except after 9 months of follow-up (43\%; Table 2).

\section{Divided attention and coordination/processing speed}

Performance in divided attention (TMT B) did not change during follow-up when compared to the post-treatment assessment (Fig. 3c). Although the z-score was close to normal at the 18 months follow-up assessment (z-score $=-1.1$ ), attention remained impaired during follow-up. On 
Fig. 3 (continued)

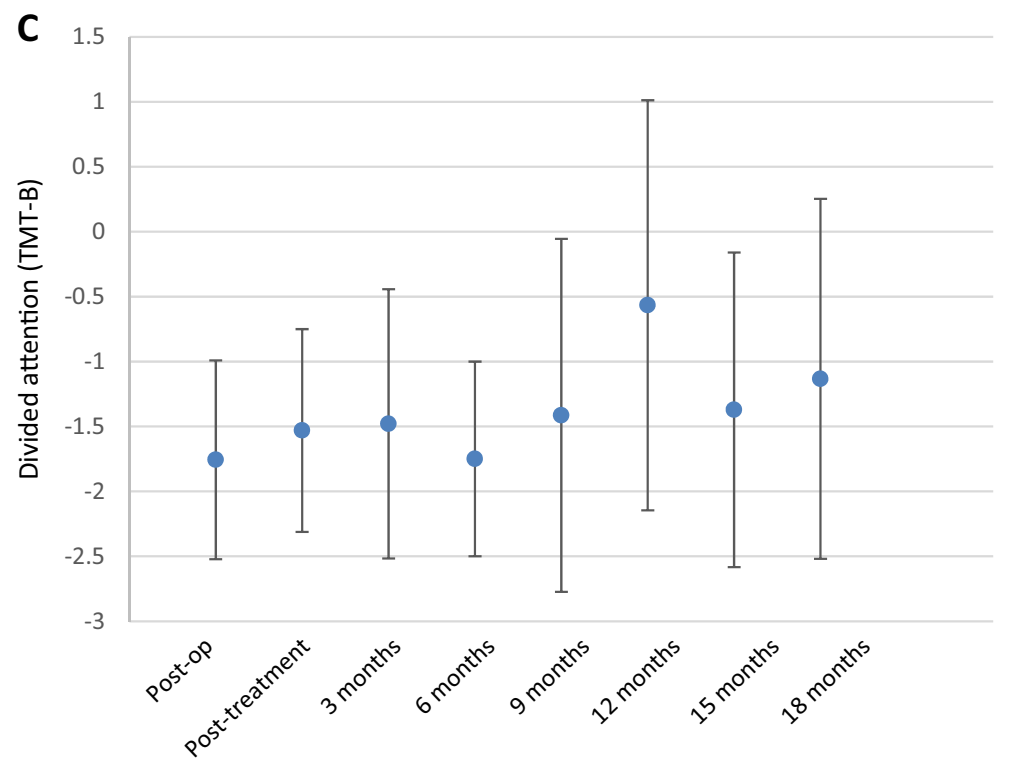

Number of patients with neurocognitive data

$\begin{array}{lllllllll}14 & 16 & 10 & 10 & 7 & 6 & 7 & 6\end{array}$

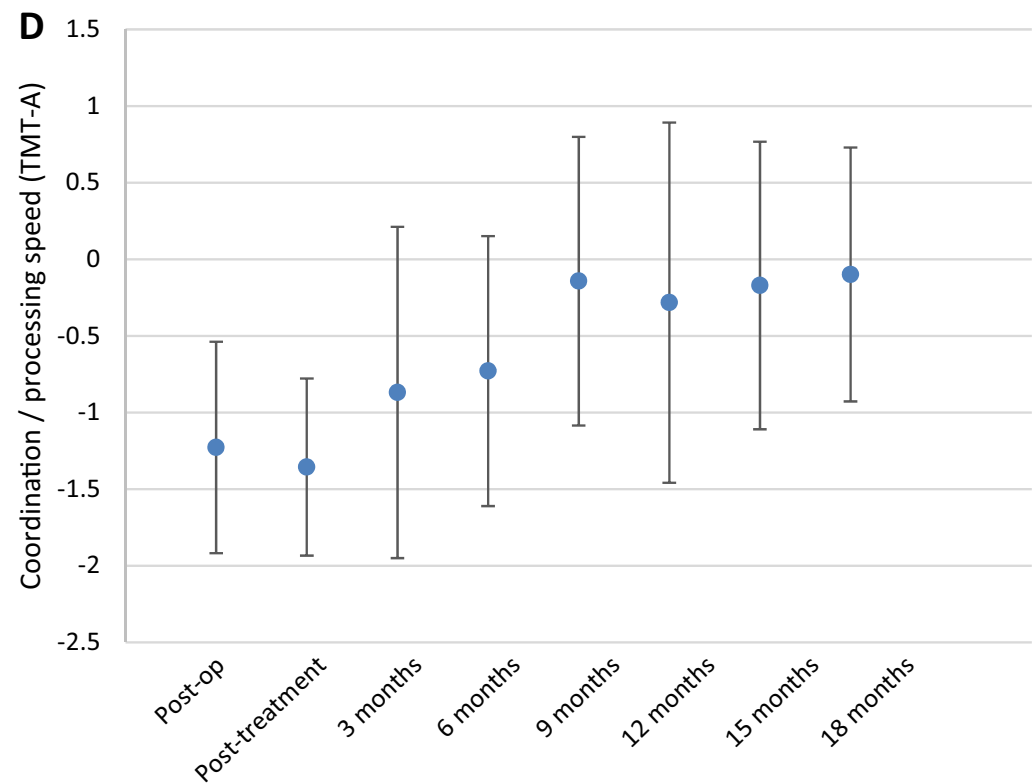

Number of patients with neurocognitive data

the individual level it was also shown that the majority of patients, except for the 12-month assessment $(33 \%$ impaired), had impaired divided attention.

Coordination/processing speed (TMT A) was impaired during the post-treatment assessment $(\mathrm{z}$-score $=-1.4)$, but improved into the normal range at 3 months follow-up ( $\mathrm{z}$-score $=-0.9, \mathrm{p}=0.028)$ and remained stable afterwards (Fig. 3d). Indeed, during the post-treatment assessment, 63\% of patients had impaired coordination/processing speed, which decreased to $17-50 \%$ of patients during follow-up.

\section{Verbal fluency}

Lexical word fluency was impaired to a clinically relevant extent before and directly after treatment, but improved during follow-up, with scores ranging between -0.1 and -0.8 (Fig. 3e), which are in the normal range. Compared to the post-treatment assessment, patients had significantly and clinically relevant better $\mathrm{z}$-scores at 9-, 12- and 15-months follow-up (all $\mathrm{p}<0.05$ ). This was also reflected on the individual patient level, where $71 \%$ of patients had impaired 
Fig. 3 (continued)

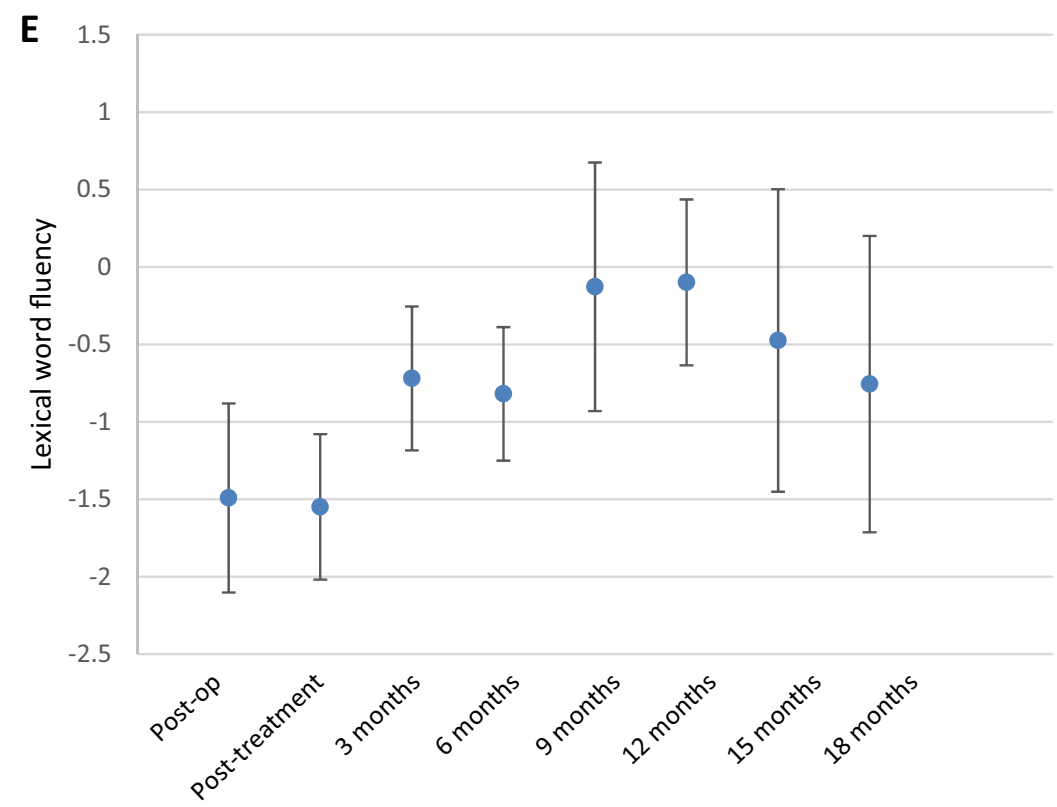

Number of patients with neurocognitive data

$\begin{array}{llllllll}13 & 14 & 10 & 10 & 7 & 6 & 8 & 6\end{array}$

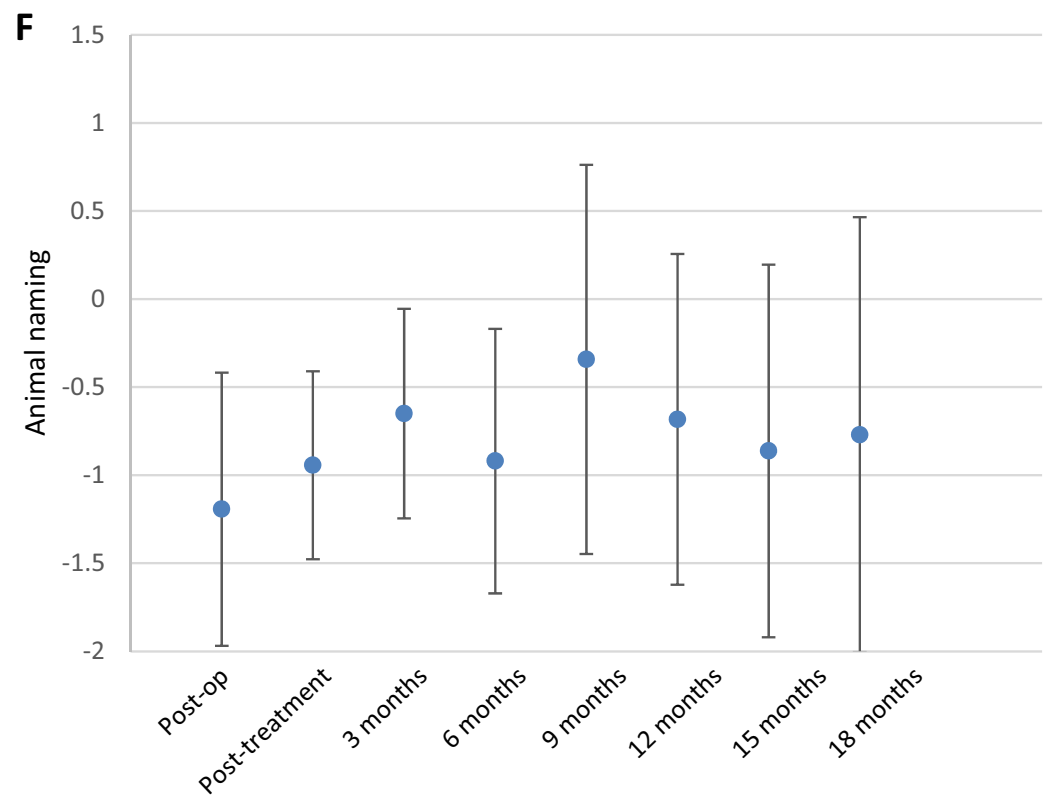

Number of patients with neurocognitive data

lexical word fluency during the post-treatment assessment, and between 17 and $43 \%$ during follow-up (Table 2).

For the animal naming test, the post-treatment score was in the normal range, which was continued during follow-up, with no significant differences between the posttreatment and follow-up z-scores (Fig. 3f). Although in the normal range, results on the individual level showed that half of patients had impaired animal naming during the post-treatment assessment, and this percentage ranged between 10 and $50 \%$ during follow-up (Table 2).

Although the post-treatment score for food naming was impaired on the group level, follow-up scores were all in the normal range, ranging between -0.5 (3 months) and -1 (18 months) (Fig. 3g), although this improvement was neither statistically significant nor clinically relevant. Similarly, on the individual level it was shown that $50 \%$ of patients had impaired food naming during the post-treatment assessment, 
Fig. 3 (continued)

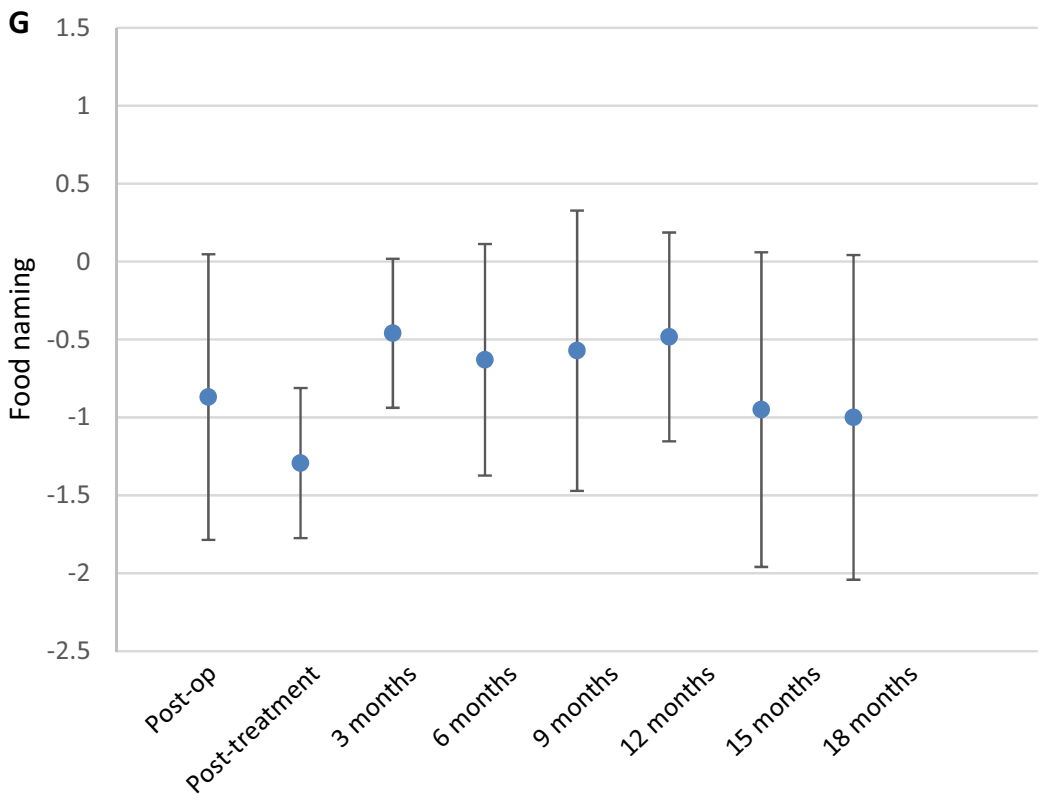

Number of patients with neurocognitive data

$\begin{array}{llllllll}13 & 14 & 10 & 10 & 7 & 6 & 8 & 7\end{array}$

and this percentage decreased (ranging between 17 and 40\%) during follow-up (Table 2).

\section{Discussion}

Treatment of adult medulloblastoma patients in the NOA-07 study with combined radiochemotherapy of the neuroaxis followed by maintenance chemotherapy with cisplatin, lomustine and vincristine has been shown, in the shortterm, to result in considerable toxicity during active treatment, however paralleled by improvements in HRQoL and neurocognitive functioning [2]. Here, we present mid- to long-term analyses on HRQoL and neurocognitive functioning, with the goal to better understand the impact of radiochemotherapy on the patients' longer term functioning and well-being. In general, this analysis showed that the NOA-07 treatment regimen on group level did not result in a (further) deterioration of HRQoL or neurocognitive functioning, except for verbal working memory, in the post-treatment period. It should be noted though, that a substantial part of the study population did experience impaired neurocognitive functioning during follow-up as shown by the analysis on the individual patient level (Table 2).

The impact of treatment on neurocognition and HRQoL in adult medulloblastoma patients is understudied. A recent study reported impaired neurocognitive functioning (learning and memory, and executive function) shortly after diagnosis [13], while another study reported that adult medulloblastoma patients had problems with executive dysfunction, weakness, ataxia, depression or anxiety about nine years after radiotherapy [14]. These long-term sequelae may subsequently have a negative impact on HRQoL. In NOA-07 study, HRQoL scores remained lower than in healthy controls [2], as did neurocognitive scores. In pediatric patients, severe and persistent deficits in neurocognitive functioning were observed after median 10 years posttreatment with radiotherapy and/ or chemotherapy, with significant impairments in aspects of daily living [31, 32], but not HRQoL [32]. Another study reported no long-term impact on HRQoL 6 years after proton therapy, although scores were below those of healthy controls [33]. Besides neurocognitive impairments, survivors of childhood medulloblastoma also often experience neurological deficits such as hearing loss and endocrine dysfunction [15], which have shown to negatively impact HRQoL in patients with pituitary adenoma [34] or vestibular schwannoma [35].

As medulloblastoma in adults typically affects younger patients, long-term social outcome of treatment is of main interest. This study showed that social functioning as measured with the EORTC QLQ-C30, reflecting the impact of disease and treatment on the patient's family and social life, improved over time, although scores remained well below that of the general population [36]. Other important survivorship issues [37], such as career opportunities and limiting of life plans/goals are currently investigated only in childhood medulloblastoma [38]. Certainly, a broader approach would provide more insight into the long-term disease burden in this disease. Adding items from the EORTC item Library [39] to the core HRQoL questionnaire and brain tumor module would be an option to fulfil this goal. 
In the 18-month post-treatment period of NOA-07, we observed clinically relevant dysfunction in the domains divided attention and working memory, which remained stable over time. Indeed, over time, the majority of patients experienced impairments in these domains. Previous studies have shown that isolated cerebellar lesions can cause impairments in working memory [19]. There is also mounting evidence that the cerebellum not only participates in working memory, but also in other higher-order cognitive tasks such as executive processing, verbal fluency and planning as well as linguistic and affective performance [16-18]. An anatomical substrate for these functions is a cerebellar feedback loop through the thalamus and prefrontal and inferior parietal lobule of the parietal cortex as reported for primates. Therefore, a major cause of neurocognitive dysfunction in these tumors seems tumor location. Nevertheless, in children it has been shown that craniospinal radiotherapy with posterior fossa boost has an additional severe negative impact on neurocognition [40-43]. This effect may be less pronounced in young adults or too early to be detected. In patients with low-grade glioma, the presence of a tumor had the most detrimental impact on the patient's neurocognitive functioning. Treatment with radiotherapy in fractions $>2$ Gy did result in neurocognitive dysfunction after a median of six years after diagnosis [44], and after a median of 12 years after diagnosis also fractions $\leq 2$ Gy were associated with neurocognitive dysfunction [12]. Radiotherapy dose reduction has impact on reducing neurocognitive toxicity. Long-term radiotherapyinduced structural sequelae as leukoencephalopathy and radiation-induced vasculopathy relate to neurocognitive deficits [45, 46]. Neurocognitive impairment after cranial irradiation is more severe in children, but also prevalent in adults [14]. The boost radiotherapy volume can be reduced to the tumor bed only in children without losing efficacy in comparison to posterior fossa irradiation, if a dose of $50 \mathrm{~Gy}$ is sustained [47, 48]. Also, a reduction of the craniospinal dose to $23.4 \mathrm{~Gy}$ in combination with chemotherapy has been investigated in pediatric trials and showed non-inferior efficacy [49]. However, both approaches were not investigated in adults in a prospective manner so far. As there is mounting evidence from pediatric trials that radiotherapy dose is associated with neurocognitive dysfunction, efforts to reduce radiotherapy dose and boost volume should be undertaken in well-selected adult medulloblastoma patients, without compromising tumor control.

The association between neurocognitive functioning and HRQoL has already been shown in patients with brain tumors, but not in adults with medulloblastoma, with worse HRQoL scores in patients with impaired neurocognitive functioning [50]. Although the limited sample size in NOA-07 refrained us from analyzing whether a change in neurocognitive functioning was associated with a change in HRQoL, we would expect that impaired neurocognition has a negative impact on the patients' HRQoL, particularly on the longer term.
Due to the small sample size and decreasing compliance over time, a common problem with neurocognitive and HRQoL assessments during follow-up in prospective brain tumor studies [51-54], long-term analysis of neurocognitive functioning beyond 18 months was not possible. In general, longer term results for both neurocognition and HRQoL should be interpreted with caution, as patients with better prognosis or good response to treatment are typically overrepresented during follow-up [55-57]. The finding that HRQoL improved up to 30 months after which a deterioration was observed, is likely caused by drop-out of patients over time, and is not necessarily a reflection of the development of long-term toxicity. This is supported by our sub-analysis in those patients with follow-up $\geq 36$ months, showing that social, role and cognitive functioning improved or remained stable in the post-treatment period. Another limitation is that this study reflects a trial population, with stringent inclusion criteria, hampering generalizability of the results to the entire adult medulloblastoma patient population. Moreover, both neurocognition and HRQoL are impacted by other factors than treatment alone, including age, tumor course, comorbidity and supportive treatment $[58,59]$. According to this, in glioma patients, progression was found to be the main cause of deterioration in HRQoL, and not treatment [60]. Due to the limited number of patients with progression and available neurocognitive or HRQoL data at the moment of progression, the impact of progression of the patients' functioning and well-being could not be evaluated in this study. Similarly, subgroup analyses were not considered meaningful because of the small sample size, while certain aspects may be associated with neurocognitive functioning and possibly HRQoL. For example, different molecular subtypes and germline polymorphisms [61] have shown to be associated with neurocognitive functioning in childhood medulloblastoma patients, and patients who did or did not complete the entire treatment regimen may also differ in their level of functioning. Lastly, changes in neurocognition and HRQoL on the individual patient level were not considered meaningful due to the limited number of patients available for analysis, even though these analyses may provide more detailed information on the impact of treatment. Indeed, presenting data on group level only may result in an underestimation of the actual problems.

In conclusion, posttreatment data of the NOA-07 study showed that combined radiochemotherapy followed by maintenance chemotherapy in general does not result in a deterioration of the functioning and well-being of adult medulloblastoma patients on the medium long term. Nevertheless, a larger adequately powered trial with a higher number of patients is needed to confirm these findings, and to prove the benefits of reduced radiotherapy dose and boost volume in adult medulloblastoma patients. Currently, a large international trial, EORTC 1634-BTG, is 
being developed at the EORTC to investigate a personalized intensity-modulated therapy in post-pubertal patients with newly-diagnosed medulloblastoma, in which neurocognitive functioning and HRQoL are included as major secondary outcomes.

Acknowledgements Open Access funding provided by Projekt DEAL.

Funding The NOA-07 study was supported by internal Grants from `n unrestricted educational Grant from medac $\mathrm{GmbH}$.

Open Access This article is licensed under a Creative Commons Attribution 4.0 International License, which permits use, sharing, adaptation, distribution and reproduction in any medium or format, as long as you give appropriate credit to the original author(s) and the source, provide a link to the Creative Commons licence, and indicate if changes were made. The images or other third party material in this article are included in the article's Creative Commons licence, unless indicated otherwise in a credit line to the material. If material is not included in the article's Creative Commons licence and your intended use is not permitted by statutory regulation or exceeds the permitted use, you will need to obtain permission directly from the copyright holder. To view a copy of this licence, visit http://creativecommons.org/licenses/by/4.0/.

\section{References}

1. Khanna V, Achey RL, Ostrom QT et al (2017) Incidence and survival trends for medulloblastomas in the United States from 2001 to 2013. J Neurooncol 135(3):433-441

2. Beier D, Proescholdt M, Reinert C et al (2018) Multicenter pilot study of radiochemotherapy as first-line treatment for adults with medulloblastoma (NOA-07). Neuro-oncology 20(3):400-410

3. Friedrich C, von Bueren AO, von Hoff K et al (2013) Treatment of adult nonmetastatic medulloblastoma patients according to the paediatric HIT 2000 protocol: a prospective observational multicentre study. Eur J Cancer 49(4):893-903

4. Kann BH, Lester-Coll NH, Park HS et al (2017) Adjuvant chemotherapy and overall survival in adult medulloblastoma. Neurooncology 19(2):259-269

5. Wang J, Garancher A, Ramaswamy V, Wechsler-Reya RJ (2018) Medulloblastoma: from molecular subgroups to molecular targeted therapies. Annu Rev Neurosci 41:207-232

6. Li Q, Dai Z, Cao Y, Wang L (2018) Comparing children and adults with medulloblastoma: a SEER based analysis. Oncotarget 9(53):30189-30198

7. Northcott PA, Hielscher T, Dubuc A et al (2011) Pediatric and adult sonic hedgehog medulloblastomas are clinically and molecularly distinct. Acta Neuropathol 122(2):231-240

8. Remke M, Hielscher T, Northcott PA et al (2011) Adult medulloblastoma comprises three major molecular variants. J Clin Oncol 29(19):2717-2723

9. Brandes AA, Palmisano V, Monfardini S (1999) Medulloblastoma in adults: clinical characteristics and treatment. Cancer Treat Rev 25(1):3-12

10. Millard NE, De Braganca KC (2016) Medulloblastoma. J Child Neurol 31(12):1341-1353

11. von Bueren AO, Friedrich C, von Hoff K et al (2015) Metastatic medulloblastoma in adults: outcome of patients treated according to the HIT2000 protocol. Eur J Cancer 51(16):2434-2443
12. Douw L, Klein M, Fagel SS et al (2009) Cognitive and radiological effects of radiotherapy in patients with low-grade glioma: long-term follow-up. Lancet Neurol 8(9):810-818

13. Harrison RA, Kesler SR, Johnson JM, Penas-Prado M, Sullaway CM, Wefel JS (2019) Neurocognitive dysfunction in adult cerebellar medulloblastoma. Psycho-oncology 28(1):131-138

14. De B, Beal K, De Braganca KC et al (2018) Long-term outcomes of adult medulloblastoma patients treated with radiotherapy. J Neurooncol 136(1):95-104

15. Chevignard M, Camara-Costa H, Doz F, Dellatolas G (2017) Core deficits and quality of survival after childhood medulloblastoma: a review. Neuro-oncol Pract 4(2):82-97

16. Baillieux H, De Smet HJ, Dobbeleir A, Paquier PF, De Deyn PP, Marien P (2010) Cognitive and affective disturbances following focal cerebellar damage in adults: a neuropsychological and SPECT study. Cortex 46(7):869-879

17. Bostan AC, Dum RP, Strick PL (2013) Cerebellar networks with the cerebral cortex and basal ganglia. Trends Cogn Sci 17(5):241-254

18. Timmann D, Daum I (2007) Cerebellar contributions to cognitive functions: a progress report after two decades of research. Cerebellum (London, England) 6(3):159-162

19. Ziemus B, Baumann O, Luerding $R$ et al (2007) Impaired working-memory after cerebellar infarcts paralleled by changes in BOLD signal of a cortico-cerebellar circuit. Neuropsychologia 45(9):2016-2024

20. von Aster M, Neubauer A, Horn R (2009) Wechsler Intelligenztest für Erwachsene WIE, 2nd edn. Pearson Assessment \& Information $\mathrm{GmbH}$, Frankfurt/M

21. Tombaugh TN (2004) Trail Making Test A and B: normative data stratified by age and education. Arch Clin Neuropsychol 19(2):203-214

22. Benton AL, Hamsher K (1989) Multilingual aphasia examination. AJA Associates, Iowa City, IA

23. Aschenbrenner S, Tucha O, Lange KW (2000) Regensburger Wortflüssigkeitstest RWT Handanweisung. Hogrefe, Seattle

24. Beglinger LJ, Gaydos B, Tangphao-Daniels O et al (2005) Practice effects and the use of alternate forms in serial neuropsychological testing. Arch Clin Neuropsychol 20(4):517-529

25. Heo JH, Lee KM, Paek SH et al (2008) The effects of bilateral subthalamic nucleus deep brain stimulation (STN DBS) on $\operatorname{cog}$ nition in Parkinson disease. J Neurol Sci 273(1-2):19-24

26. Aaronson NK, Ahmedzai S, Bergman B et al (1993) The European Organization for Research and Treatment of Cancer QLQC30: a quality-of-life instrument for use in international clinical trials in oncology. J Natl Cancer Inst 85(5):365-376

27. Osoba D, Aaronson NK, Muller M et al (1996) The development and psychometric validation of a brain cancer quality-of-life questionnaire for use in combination with general cancer-specific questionnaires. Qual Life Res 5(1):139-150

28. Taphoorn MJ, Claassens L, Aaronson NK et al (2010) An international validation study of the EORTC brain cancer module (EORTC QLQ-BN20) for assessing health-related quality of life and symptoms in brain cancer patients. Eur J Cancer 46(6): 1033-1040

29. Fayers PM, Aaronson NK, Bjordal K, Groenvold M, Curran D, Bottomley A (2001) The EORTC QLQ-C30 scoring manual, 3rd edn. European Organisation for Research and Treatment of Cancer, Brussels

30. Osoba D, Rodrigues G, Myles J, Zee B, Pater J (1998) Interpreting the significance of changes in health-related quality-of-life scores. J Clin Oncol 16(1):139-144

31. Frange P, Alapetite C, Gaboriaud G et al (2009) From childhood to adulthood: long-term outcome of medulloblastoma patients. The Institut Curie experience (1980-2000). J Neuro-oncology 95(2):271-279 
32. Maddrey AM, Bergeron JA, Lombardo ER et al (2005) Neuropsychological performance and quality of life of 10 year survivors of childhood medulloblastoma. J Neurooncol 72(3):245-253

33. Kamran SC, Goldberg SI, Kuhlthau KA et al (2018) Quality of life in patients with proton-treated pediatric medulloblastoma: Results of a prospective assessment with 5-year follow-up. Cancer 124(16):3390-3400

34. van der Klaauw AA, Kars M, Biermasz NR et al (2008) Diseasespecific impairments in quality of life during long-term followup of patients with different pituitary adenomas. Clin Endocrinol 69(5):775-784

35. Berkowitz O, Han YY, Talbott EO et al (2017) Gamma Knife Radiosurgery for Vestibular Schwannomas and Quality of Life Evaluation. Stereotact Funct Neurosurg 95(3):166-173

36. van de Poll-Franse LV, Mols F, Gundy CM et al (2011) Normative data for the EORTC QLQ-C30 and EORTC-sexuality items in the general Dutch population. Eur J Cancer 47(5):667-675

37. van Leeuwen M, Husson O, Alberti P et al (2018) Understanding the quality of life (QOL) issues in survivors of cancer: towards the development of an EORTC QOL cancer survivorship questionnaire. Health Qual Life Outcomes 16(1):114

38. Kieffer V, Chevignard MP, Dellatolas G et al (2019) Intellectual, educational, and situation-based social outcome in adult survivors of childhood medulloblastoma. Dev Neurorehabil 22(1):19-26

39. EORTC Item Library. 2019. https://www.eortc.be/itemlibrary/.

40. Grill J, Renaux VK, Bulteau C et al (1999) Long-term intellectual outcome in children with posterior fossa tumors according to radiation doses and volumes. Int $\mathrm{J}$ Radiat Oncol Biol Phys 45(1):137-145

41. Kieffer-Renaux V, Bulteau C, Grill J, Kalifa C, Viguier D, Jambaque I (2000) Patterns of neuropsychological deficits in children with medulloblastoma according to craniospatial irradiation doses. Dev Med Child Neurol 42(11):741-745

42. Moxon-Emre I, Bouffet E, Taylor MD et al (2014) Impact of craniospinal dose, boost volume, and neurologic complications on intellectual outcome in patients with medulloblastoma. J Clin Oncol 32(17):1760-1768

43. Palmer SL, Goloubeva O, Reddick WE et al (2001) Patterns of intellectual development among survivors of pediatric medulloblastoma: a longitudinal analysis. J Clin Oncol 19(8):2302-2308

44. Klein M, Heimans JJ, Aaronson NK et al (2002) Effect of radiotherapy and other treatment-related factors on mid-term to longterm cognitive sequelae in low-grade gliomas: a comparative study. Lancet (London, England) 360(9343):1361-1368

45. King AA, Seidel K, Di C et al (2017) Long-term neurologic health and psychosocial function of adult survivors of childhood medulloblastoma/PNET: a report from the Childhood Cancer Survivor Study. Neuro-oncology 19(5):689-698

46. Salloum R, Chen Y, Yasui Y et al (2019) Late morbidity and mortality among medulloblastoma survivors diagnosed across three decades: a report from the Childhood Cancer Survivor Study. J Clin Oncol 37(9):731-740

47. Michalski J, Vezina G, Burger P et al (2016) Preliminary results of COG ACNS0331: A phase III trial of involved field radiotherapy (IFRT) and low dose craniospinal irradiation (LD-CSI) with chemotherapy in average risk medulloblastoma: a report from the children's oncology group. Neuro-Oncology 96:937-938

48. Padovani L, Sunyach MP, Perol D et al (2007) Common strategy for adult and pediatric medulloblastoma: a multicenter series of 253 adults. Int J Radiat Oncol Biol Phys 68(2):433-440

49. Packer RJ, Gajjar A, Vezina G et al (2006) Phase III study of craniospinal radiation therapy followed by adjuvant chemotherapy for newly diagnosed average-risk medulloblastoma. J Clin Oncol 24(25):4202-4208

50. Boele FW, Zant M, Heine EC et al (2014) The association between cognitive functioning and health-related quality of life in lowgrade glioma patients. Neuro-oncology Pract 1(2):40-46

51. Habets EJ, Dirven L, Wiggenraad RG et al (2016) Neurocognitive functioning and health-related quality of life in patients treated with stereotactic radiotherapy for brain metastases: a prospective study. Neuro-oncology 18(3):435-444

52. Herrlinger U, Schafer N, Fimmers R et al (2017) Early whole brain radiotherapy in primary CNS lymphoma: negative impact on quality of life in the randomized G-PCNSL-SG1 trial. J Cancer Res Clin Oncol 143(9):1815-1821

53. Reijneveld JC, Taphoorn MJ, Coens C et al (2016) Healthrelated quality of life in patients with high-risk low-grade glioma (EORTC 22033-26033): a randomised, open-label, phase 3 intergroup study. Lancet Oncol 17(11):1533-1542

54. Taphoorn MJ, Henriksson R, Bottomley A et al (2015) Healthrelated quality of life in a randomized phase iii study of bevacizumab, temozolomide, and radiotherapy in newly diagnosed glioblastoma. J Clin Oncol 33(19):2166-2175

55. Renovanz M, Hechtner M, Kohlmann K et al (2018) Compliance with patient-reported outcome assessment in glioma patients: predictors for drop out. Neuro-oncology Pract 5(2):129-138

56. Vordermark D (2007) Avoiding bias in the prospective evaluation of patients with brain metastases. J Clin Oncol 25(25):4023

57. Walker M, Brown J, Brown K, Gregor A, Whittle IR, Grant R (2003) Practical problems with the collection and interpretation of serial quality of life assessments in patients with malignant glioma. J Neurooncol 63(2):179-186

58. Armstrong TS, Ying Y, Wu J et al (2015) The relationship between corticosteroids and symptoms in patients with primary brain tumors: utility of the Dexamethasone Symptom Questionnaire-Chronic. Neuro-oncology 17(8):1114-1120

59. Klein M, Engelberts NH, van der Ploeg HM et al (2003) Epilepsy in low-grade gliomas: the impact on cognitive function and quality of life. Ann Neurol 54(4):514-520

60. Dirven L, van den Bent MJ, Bottomley A et al (2015) The impact of bevacizumab on health-related quality of life in patients treated for recurrent glioblastoma: results of the randomised controlled phase 2 BELOB trial. Eur J Cancer 51(10):1321-1330

61. Oyefiade A, Erdman L, Goldenberg A et al (2019) PPAR and GST polymorphisms may predict changes in intellectual functioning in medulloblastoma survivors. J Neurooncol 142(1):39-48

Publisher's Note Springer Nature remains neutral with regard to jurisdictional claims in published maps and institutional affiliations.

\title{
Affiliations
}

\author{
Linda Dirven ${ }^{1,2}$. Ralf Luerding ${ }^{3}$. Dagmar Beier ${ }^{4}$ Elisabeth Bumes ${ }^{3} \cdot$ Christiane Reinert $^{3,5} \cdot$ Clemens Seidel $^{6}$. \\ Matteo Mario Bonsanto ${ }^{7}$. Michael Bremer ${ }^{8}$. Stefan Rieken ${ }^{9}$. Stephanie E. Combs ${ }^{10,11,12}$. Ulrich Herrlinger ${ }^{13}$. \\ Corinna Seliger ${ }^{3,14,15} \cdot$ Holger Kuntze $^{16} \cdot$ Regine Mayer-Steinacker $^{17} \cdot$ Annette Dieing $^{18} \cdot$ Claudius Bartels $^{19}$. \\ Oliver Schnell ${ }^{20}$. Astrid Weyerbrock ${ }^{20}$. Sabine Seidel ${ }^{21}$. Oliver Grauer ${ }^{22} \cdot$ Minou Nadji-Ohl $^{23}$. Frank Paulsen ${ }^{24}$. \\ Michael Weller ${ }^{25}$. Wolfgang Wick ${ }^{14,15} \cdot$ Peter Hau $^{3}$
}


Linda Dirven

1.dirven@lumc.nl

Ralf Luerding

ralf.luerding@medbo.de

Dagmar Beier

dagmar.beier@rsyd.dk

Elisabeth Bumes

elisabeth.bumes@ukr.de

Christiane Reinert

Christiane.Reinert@barmherzige-regensburg.de

Clemens Seidel

clemens.seidel@medizin.uni-leipzig.de

Matteo Mario Bonsanto

matteo.bonsanto@uksh.de

Michael Bremer

bremer.michael@mh-hannover.de

Stefan Rieken

stefan.rieken@med.uni-goettingen.de

Stephanie E. Combs

Stephanie.Combs@tum.de

Ulrich Herrlinger

ulrich.herrlinger@ukb.uni-bonn.de

Corinna Seliger

Corinna.Seliger@klinik.uni-regensburg.de;

corinna.seliger-behme@med.uni-heidelberg.de

Holger Kuntze

holger.kuntze@unimedizin-mainz.de

Regine Mayer-Steinacker

regine.mayer-steinacker@uniklinik-ulm.de

Annette Dieing

annette.dieing@vivantes.de

Claudius Bartels

claudius.bartels@med.ovgu.de

Oliver Schnell

oliver.schnell@uniklinik-freiburg.de

Astrid Weyerbrock

Astrid.weyerbrock@uniklinik-freiburg.de

Sabine Seidel

sabine.seidel@kk-bochum.de

Oliver Grauer

oliver.grauer@ukmuenster.de

Minou Nadji-Ohl

m.nadji-ohl@klinikum-stuttgart.de

Frank Paulsen

frank.paulsen@med.uni-tuebingen.de

Michael Weller

michael.weller@usz.ch

Wolfgang Wick

wolfgang.wick@med.uni-heidelberg.de

1 Department of Neurology, Leiden University Medical Center, Leiden, The Netherlands
2 Department of Neurology, Haaglanden Medical Center, The Hague, The Netherlands

3 Wilhelm Sander-NeuroOncology Unit and Department of Neurology, University of Regensburg, Regensburg, Germany

4 Department of Neurology, University Hospital Odense and Clinical Institute, University of Southern Denmark, Odense, Denmark

5 Department of Oncology, Krankenhaus der Barmherzigen Brüder Regensburg, Regensburg, Germany

6 Department of Radiation Oncology, University Hospital Leipzig, Leipzig, Germany

7 Department of Neurosurgery, University Hospital, Lübeck, Germany

8 Department of Radiation Oncology, Medical School Hannover, Hannover, Germany

9 Department of Radiotherapy and Radiation Oncology, University Hospital Göttingen, Göttingen, Germany

10 Department of Radiation Oncology, Technical University of Munich, Munich, Germany

11 Institute of Radiation Medicine, Helmholtz Zentrum Münche, Oberschleißheim, Germany

12 Deutsches Konsortium für Translationale Krebsforschung (DKTK), Partner Site Munich, Munich, Germany

13 Division of Neurooncology, University of Bonn Medical Center, Bonn, Germany

14 Department of Neurology, University Hospital Heidelberg, Heidelberg, Germany

15 Neurooncology Program at the National Center for Tumor Diseases, German Cancer Research Center (DKFZ)/DKTK, Heidelberg, Germany

16 Department of Neurology, University Hospital Mainz, Mainz, Germany

17 Department of Medical Oncology, University Hospital Ulm, Ulm, Germany

18 Department of Internal Medicine, Hematology and Oncology, Vivantes Klinikum am Friedrichshain, Berlin, Germany

19 Department of Neurosurgery, University Hospital Magdeburg, Magdeburg, Germany

20 Department of Neurosurgery, University Hospital Freiburg, Freiburg, Germany

21 Department of Neurology, Knappschaftskrankenhaus, University of Bochum, Bochum, Germany

22 Department of Neurology with Institute of Translational Neurology, University Hospital Münster, Münster, Germany

23 Department of Radiation Oncology, Klinikum Stuttgart, Stuttgart, Germany

24 Department of Radiation Oncology, University Hospital Tübingen, Tübingen, Germany

25 Department of Neurology, University Hospital and University of Zurich, Zurich, Switzerland 